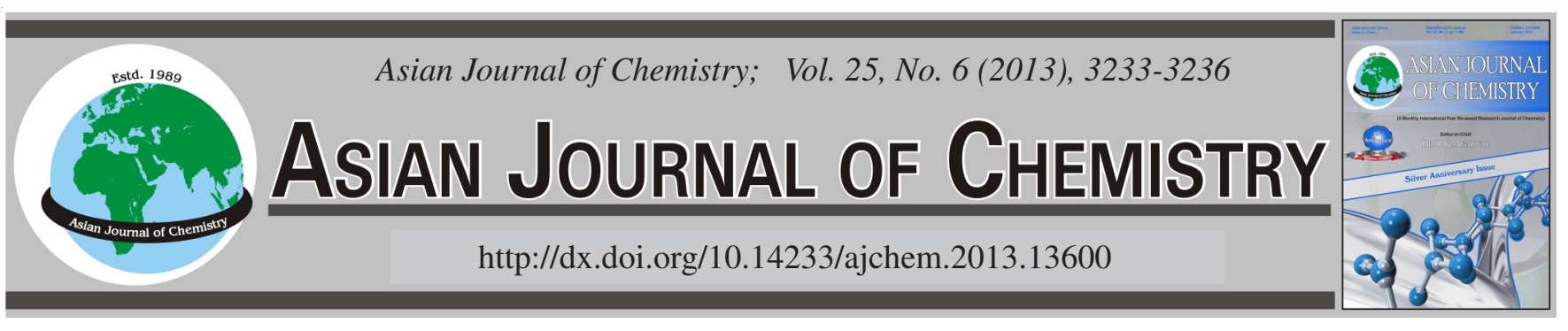

\title{
Structure and Spectral Studies of $N$-Ethyl Pyridinium Bromide Ionic Liquids: DFT and ab initio Study
}

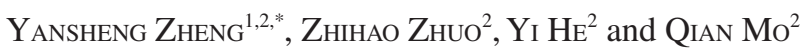

${ }^{1}$ Lushan College of Guangxi University of Technology, Luzhou 545616, Guangxi Province, P.R. China

${ }^{2}$ Department of Biological and Chemical Engineering, Guangxi University of Technology, Liuzhou 545006, Guangxi Province, P.R. China

*Corresponding author: Fax: +86 772 2687033; Tel: +86 772 2685962; E-mail: zhyansh88@163.com

(Received: 15 February 2012;

Accepted: 14 December 2012)

AJC-12555

\begin{abstract}
Ionic liquids, due to their unique properties and solvent capabilities, have aroused wide concern and much potential utility value investigation have been carried out. In this article, the constitutive property and spectroscopy have been calculated by density function theory B3LYP, B3PW91 and (ab initio) HF at 6-31G+(d,p) and 6-311G+(d,p) level for the ionic liquid $N$-ethyl yridinium bromide ([EPy]Br). The assignment of atomic charge and the IR spectra have been respectively obtained by natural bond orbital analysis and vibration analysis. Compared experimental IR frequency and calculated. And then this paper sumed up and analyzed vibration frequencies. The results show that some charges have transferred between the anion and cation and IR characteristic spectrum of theoretical calculation is consistent with experimental result for the B3PW91 and HF methods using the 6-311G+(d,p).
\end{abstract}

Key Words: Ionic liquids, $N$-Ethyl pyridinium bromide, $a b$ initio, Density function theory.

\section{INTRODUCTION}

Within the last two decades, ionic liquids have attracted rising interest with a diversified range of applications. Ionic liquids are salts with a melting point below $373 \mathrm{~K}$ and hence are liquid at moderate temperature, defined as liquids composed of organic cations and inorganic anions ${ }^{1,2}$. Owing to their ionic nature, many ionic liquids exhibit characteristics such as non-volatility, non-flammability, high electro-conductivity and good thermal stability ${ }^{3}$. The use of ionic liquids has proved beneficial in numerous areas including those of sensors, fuel cells, batteries, capacitors, thermal analysis, synthesis, catalysis, separation and so on ${ }^{4}$. In order to implement successful in most new applications, a full and detailed understanding of interrelations between the structure and properties of ionic liquids ${ }^{5}$ and obtaining of reliable date on the structure and bonding in ionic liquids are obviously very important.

The method of quantum chemical calculation is used to determine interaction energies ${ }^{6,7}$, thermodynamic properties ${ }^{8,9}$ and also find a correlation between structure and property of ion-pairs. The $a b$ initio and density function theory calculations both have been used to investigate structure properties and predict vibrational frequencies ${ }^{10}$ of some ionic liquids. Pakiari et al. ${ }^{11}$ studied 15 aprotic ionic liquids using density function theory and found that the relationship between the structure of counter-ions and inter-ionic interaction in ion-pairs.
In this study, we chose $N$-ethyl pyridimium bromide [Epy] $\mathrm{Br}$ to determine the structure of the pyridimium cation and to investigate the IR spectra. Bromide ion, as most simple anion, make it possible to focus on conformational analyses of the cation only. The assignment of atomic charge and the IR spectra have been obtained by natural bond orbital analysis and vibration analysis, respectively. Compared experimental IR frequency and calculated and then sumed up and analyzed vibration frequencies.

\section{EXPERIMENTAL}

Model build and computational methods: The molecular structure and atomic symbol of $N$-ethyl-pyridine bromide ([EPy] Br) were shown in Fig. 1.The 3D model of [EPy] $\mathrm{Br}$ were optimized by Semi-empirical PM3 method, the most stable molecular structure were optimized by density functional theory method at B3LYP/6-31G + (d,p), B3LYP/6-311G + (d, p) and B3PW91/6-311G + (d,p) levels. The structural parameters such as bond length, bond angle, dihedral angle were analyzed. The charge distribution of the atoms were obtained by natural bond orbital analysis. The vibration frequency and intensity of [EPy]Br were obtained by vibration analysis), continuous infrared spectra figure were got by program transformation). Meanwhile, ab initio (ab initio) HF/6-31G + $(\mathrm{d}, \mathrm{p})$ and HF/6-311G + (d, p) method were compared. All calculations completed in the PC-Pentium (R) 2.0 G. 
<smiles>[1H]c1ccc2cccc[n+]2c1</smiles>

Fig. 1. Structure of [EPy]Br

\section{RESULTS AND DISCUSSION}

Molecular structure: The molecular structures of $\mathrm{N}$ ethyl-pyridine cation $\left([\mathrm{EPy}]^{+}\right)$and $N$-ethyl-pyridine bromide ([EPy] Br) were determined at the B3LYP/6-311G + (d,p), its molecular structure were obtained (Fig. 2). The structural data such as bond lengths, bond angles, dihedral angle and charge distribution were optimized in each method and basis set (Tables 1-3).

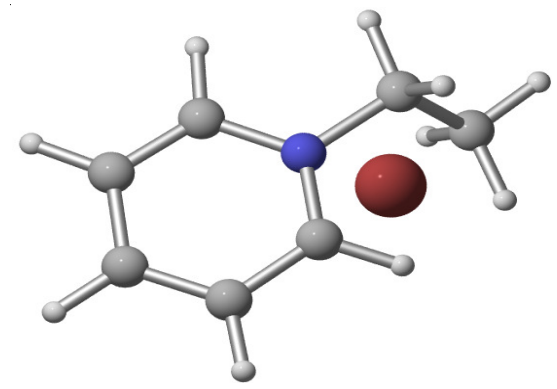

Fig. 2. Optimized structures of [EPy]Br, B3LYP/6-311G + (d,p)

\begin{tabular}{cccccc}
\multicolumn{7}{c}{ TABLE-1 } \\
\multicolumn{7}{c}{ COMPARED CALCULATION OF BOND LENGTH OF } \\
& B3LYP/6- & B3LYP/6- & B3PW91/6- & HF/6- & HF/6- \\
& 31+G & 311+G & 311+G & $31+G$ & $311+\mathrm{G}$ \\
& $(\mathrm{d}, \mathrm{p})$ & $(\mathrm{d}, \mathrm{p})$ & $(\mathrm{d}, \mathrm{p})$ & $(\mathrm{d}, \mathrm{p})$ & $(\mathrm{d}, \mathrm{p})$ \\
\hline C1-C2 & 0.1414 & 0.1404 & 0.1409 & 0.1385 & 0.1384 \\
C1-C3 & 0.1374 & 0.1374 & 0.1369 & 0.1373 & 0.1372 \\
C3-C4 & 0.1417 & 0.1411 & 0.1412 & 0.1397 & 0.1397 \\
C4-C5 & 0.1371 & 0.1369 & 0.1365 & 0.1364 & 0.1362 \\
C2-N6 & 0.1367 & 0.1360 & 0.1360 & 0.1330 & 0.1328 \\
C5-N6 & 0.1365 & 0.1361 & 0.1359 & 0.1342 & 0.1342 \\
N6-C7 & 0.1480 & 0.1481 & 0.1471 & 0.1485 & 0.1487 \\
C7-C8 & 0.1528 & 0.1526 & 0.1520 & 0.1521 & 0.1521 \\
C1-H9 & 0.1083 & 0.1080 & 0.1082 & 0.1071 & 0.1072 \\
C2-H10 & 0.1078 & 0.1075 & 0.1077 & 0.1068 & 0.1068 \\
C3-H11 & 0.1085 & 0.1083 & 0.1084 & 0.1075 & 0.1075 \\
C4-H12 & 0.1083 & 0.1081 & 0.1082 & 0.1072 & 0.1072 \\
C5-H13 & 0.1083 & 0.1081 & 0.1082 & 0.1072 & 0.1072 \\
\hline
\end{tabular}

According to the results of [EPy]Br optimization, bond lengths and bond angles were more consistent with level of each basis set. The $\mathrm{C}-\mathrm{C}$ bond length of pyridine ring was shorter than the single $\mathrm{C}-\mathrm{C}(0.1540 \mathrm{~nm})$ and longer than the single $\mathrm{C}=\mathrm{C}(0.1340 \mathrm{~nm})$, the $\mathrm{C}-\mathrm{N}$ bond length was shorter than the single C-N $(0.1470 \mathrm{~nm})$ and longer than the single $\mathrm{C}=\mathrm{N}$
$(0.1270 \mathrm{~nm})$, that the single bond and double bond of pyridine ring has the average trend on the bond length. When [EPy ${ }^{+}$ and $\mathrm{Br}^{-}$formed a neutral salt, the calculated dihedral angle of $\theta_{\mathrm{C}_{2} \mathrm{~N}_{6} \mathrm{C}_{5} \mathrm{C}_{4}}$ and $\theta_{\mathrm{C}_{3} \mathrm{ClC}_{2} \mathrm{~N}_{6}}$ were largely different from which dihedral angle were $-10.8^{\circ}$ and $-11.03^{\circ}$ in the B3LYP/6-31G + (d,p) basis sets and in the HF/6-311G + (d,p) level computation were $-2.20^{\circ}$ and $-2.10^{\circ}$. The general trend is that the atoms on the pyridine ring are no longer in the same plane, because of the strong electrostatic interaction between negatively charged $\mathrm{Br}^{-}$and positively charged $[\mathrm{EPy}]^{+}$, so that the atoms N6, C1, $\mathrm{C} 3$ of pyridine ring shift to the atom $\mathrm{Br}$ and keep the pyridine ring was a little chair-type structure in the end but the pyridine ring is still a conjugated system.

\begin{tabular}{cccccc}
\multicolumn{5}{c}{ TABLE-2 } \\
COMPARED CALCULATION OF BOND ANGLE AND DIHEDRAL \\
ANGLE OF [EPy]Br AT DIFFERENT LEVEL $\theta\left(^{\circ}\right)$ \\
\hline $\begin{array}{c}\text { B3LYP/6- } \\
\text { 31+G }\end{array}$ & B3LYP/6- & B3PW91/6- & HF/6- & HF/6- \\
& (d,p) & $(\mathrm{d}, \mathrm{p})$ & $(\mathrm{d}, \mathrm{p})$ & $(\mathrm{d}, \mathrm{p})$ & $(\mathrm{d}, \mathrm{p})$ \\
\hline C1-C2-N6 & 118.7 & 119.3 & 118.7 & 120.9 & 120.8 \\
C2-N6-C5 & 120.2 & 120.6 & 120.7 & 120.6 & 120.8 \\
N6-C5-C4 & 121.3 & 121.2 & 121.3 & 121.4 & 121.4 \\
C5-C4-C3 & 118.8 & 118.9 & 118.7 & 118.5 & 118.5 \\
C4-C3-C1 & 119.5 & 119.5 & 119.6 & 119.6 & 119.6 \\
C3-C1-C2 & 119.9 & 119.8 & 119.9 & 118.8 & 118.9 \\
N6-C7-C8 & 113.0 & 113.0 & 113.0 & 112.1 & 111.9 \\
C1-C2-N6-C5 & 15.45 & 9.72 & 12.6 & 5.78 & 2.95 \\
C2-N6-C5-C4 & -10.8 & -6.91 & -8.49 & -4.31 & -2.20 \\
C4-C3-C1-C2 & 1.89 & 0.55 & 1.19 & 1.10 & 0.52 \\
C3-C1-C2-N6 & -11.03 & -6.53 & -8.95 & -4.17 & -2.10 \\
C2-C5-N6-C7 & -166.2 & -169.7 & -168.9 & -172.5 & -175.9 \\
\hline
\end{tabular}

TABLE-3

COMPARED CALCULATION OF ATOMIC CHARGES OF [EPy]Br AT DIFFERENT LEVEL

\begin{tabular}{cccccc}
\hline & $\begin{array}{c}\text { B3LYP/6- } \\
31+\mathrm{G} \\
(\mathrm{d}, \mathrm{p})\end{array}$ & $\begin{array}{c}\text { B3LYP/6- } \\
311+\mathrm{G} \\
(\mathrm{d}, \mathrm{p})\end{array}$ & $\begin{array}{c}\text { B3PW91/6- } \\
311+\mathrm{G} \\
(\mathrm{d}, \mathrm{p})\end{array}$ & $\begin{array}{c}\mathrm{HF} / 6- \\
31+\mathrm{G} \\
(\mathrm{d}, \mathrm{p})\end{array}$ & $\begin{array}{c}\text { HF/6- } \\
311+\mathrm{G} \\
(\mathrm{d}, \mathrm{p})\end{array}$ \\
\hline C1 & 0.121 & -0.069 & -0.057 & 0.031 & -0.185 \\
C2 & -0.542 & -0.300 & -0.385 & -0.260 & -0.079 \\
C3 & -0.326 & -0.233 & -0.316 & -0.347 & -0.211 \\
C4 & 0.022 & -0.132 & -0.153 & -0.017 & -0.214 \\
C5 & -0.052 & -0.043 & -0.086 & -0.072 & 0.048 \\
N6 & 0.149 & 0.274 & 0.404 & 0.038 & 0.226 \\
C7 & 0.050 & -0.144 & -0.183 & 0.004 & -0.114 \\
C8 & -0.421 & -0.391 & -0.475 & -0.354 & -0.364 \\
H9 & 0.156 & 0.161 & 0.175 & 0.214 & 0.178 \\
H10 & 0.168 & 0.216 & 0.241 & 0.287 & 0.239 \\
H15 & 0.212 & 0.212 & 0.224 & 0.235 & 0.237 \\
\hline
\end{tabular}

According to the [EPy]Br charge distribution (Table-3), the atoms of pyridine ring were all positive charge and the positive charge of atoms H9, H10, H15 were larger than others. The negative charge of atom $\mathrm{C} 2$ on [EPy] Br was larger, because there are strong electrostatic interaction between negatively charged $\mathrm{Br}^{-}$and the positively charged pyridine ring, so that $\mathrm{Br}^{-}$shift to $\mathrm{N}$ pyridine ring and locates below $\mathrm{N}$ pyridine ring. The results showed that the charge of $\mathrm{Br}^{-}$were $-0.542 \mathrm{C}$, $-0.582 \mathrm{C},-0.538 \mathrm{C}$ by B3LYP/6-31G + (d,p), B3LYP/6-311G $+(\mathrm{d}, \mathrm{p})$ and B3PW91/6-311G + (d,p) levels of computations and the charge of $[\mathrm{EPy}]^{+}$were $+0.542 \mathrm{C},+0.582 \mathrm{C},+0.538 \mathrm{C}$; the charge of $\mathrm{Br}^{-}$were $-0.828 \mathrm{C},-0.802 \mathrm{C}$ at the $\mathrm{HF} / 6-31 \mathrm{G}+$ 
$(\mathrm{d}, \mathrm{p})$ and $\mathrm{HF} / 6-311 \mathrm{G}+(\mathrm{d}, \mathrm{p})$ levels of computations and the charge of $[\mathrm{EPy}]+$ were $+0.828 \mathrm{C},+0.802 \mathrm{C}$. The data above shows [EPy]Br have strong anion-cation interactions (ion-pair effect), owing to some charge from the anion to cation, so the ions remain electric neutrality.

Infrared spectrum: The vibration frequency of each chemical bonds and experimental data were obtained from vibration analysis of optimization. The results of the theoretical and experimental vibrational bands from B3LYP/6-31G+ $(\mathrm{d}, \mathrm{p})$ to B3LYP/6-311G + (d,p) (Fig. 3) to B3PW91/6-311G + $(\mathrm{d}, \mathrm{p})$ to $\mathrm{HF} / 6-31 \mathrm{G}+(\mathrm{d}, \mathrm{p})$ to $\mathrm{HF} / 6-311 \mathrm{G}+(\mathrm{d}, \mathrm{p})$ with the slopes from 0.9982 to 1.0038 to 0.99859 to 0.99859 to 0.9877 . The slopes are representative of scale factors of 0.9982 [B3LYP/ $6-31 G+(d, p)], 0.9962$ [B3LYP/6-311G + (d,p)], 0.9986 [B3PW91/6-311G + (d,p)], $0.9986[\mathrm{HF} / 6-31 \mathrm{G}+(\mathrm{d}, \mathrm{p})]$ and $0.9987[\mathrm{HF} / 6-311 \mathrm{G}+(\mathrm{d}, \mathrm{p})]$ all very close to 1 , indicating that the above calculated infrared vibrational frequencies and the experimental dates are consistent in all different calculation methods and basis sets. Comparison of HF/6-31G $+(d, p)$ and $\mathrm{HF} / 6-311 \mathrm{G}+(\mathrm{d}, \mathrm{p})$ levels of computations showed that the data is very close. In comparison with the experimental results and calculation of two density function theory methods, the B3PW91 methods consistent higher than the B3LYP method but also the corresponding cost of computation is higher too.

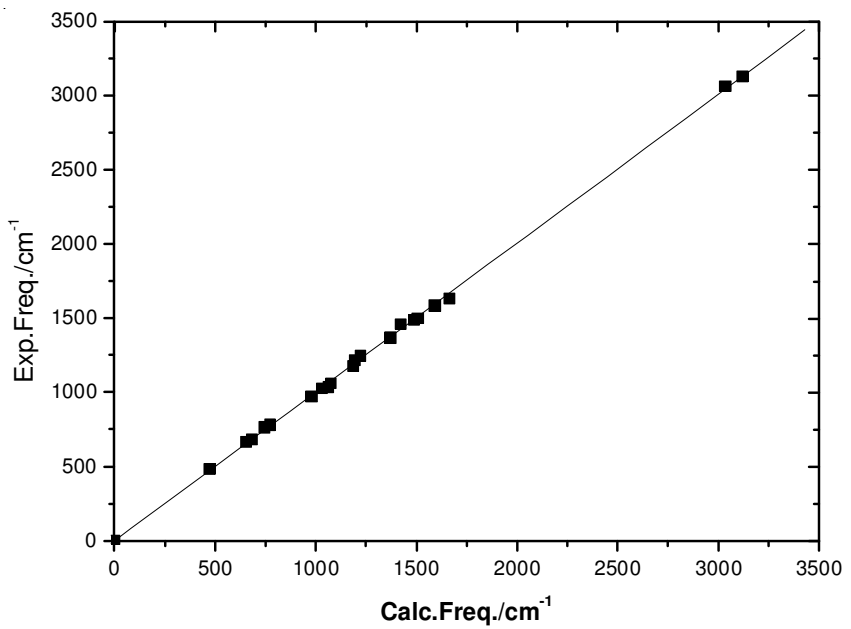

Fig. 3. Experimental frequency $\left(\mathrm{cm}^{-1}\right) v s$. calculated frequency $\left(\mathrm{cm}^{-1}\right)$ for [EPy]Br by B3LYP/6-311G + (d,p), slope $=1.0038$

The [EPy]Br calculated vibrational Assignments using in HF/6-311G + (d,p) method were shown in Table-4. The frequency of each absorption peak corresponding to the vibration mode were analyzed, the absorption peak at $730 \mathrm{~cm}^{-1}$ is symmetric wag of $\mathrm{C}-\mathrm{H}$ in pyridine ring. The absorption peak at $847 \mathrm{~cm}^{-1}$ is due to asymmetric wag of $\mathrm{C}-\mathrm{H}$ in pyridine ring. The absorption peak at $1035 \mathrm{~cm}^{-1}$ is asymmetric wag of $\mathrm{C}-\mathrm{H}$ in ethyl group and pyridine ring. The absorption peak at 1097 $\mathrm{cm}^{-1}$ is out of plane bend of pyridine ring and asymmetric wag of $\mathrm{C}-\mathrm{H}$ in pyridine ring. The absorption peak at $1215 \mathrm{~cm}^{-1}$ is in plane scissor of $\mathrm{C}-\mathrm{H}$ in pyridine ring. The absorption peak at $1289 \mathrm{~cm}^{-1}$ is due to stretch of $\mathrm{N}-\mathrm{CH}_{2}$ and asymmetric rock of terminal $\mathrm{CH}_{3}$ group; the absorption peak of $1331 \mathrm{~cm}^{-1}$ is in plane scissor of $\mathrm{C}-\mathrm{H}$ in pyridine ring and asymmetric rock of terminal $\mathrm{CH}_{3}$ group; the absorption peak of $1607 \mathrm{~cm}^{-1}$ is asymmetric rock of terminal $\mathrm{CH}_{3}$ group. The absorption peak of $1829 \mathrm{~cm}^{-1}$ is stretch of $\mathrm{C}=\mathrm{C}$ in pyridine ring. The absorption peak of $3171 \mathrm{~cm}^{-1}$ to $3295 \mathrm{~cm}^{-1}$ is stretch of C-H in ethyl, the absorption peaks in $3437-3352 \mathrm{~cm}^{-1}$ region is due to stretch of $\mathrm{C}-\mathrm{H}$ in pyridine ring.

\begin{tabular}{|c|c|c|}
\hline \multicolumn{3}{|l|}{$\begin{array}{c}\text { TABLE-4 } \\
\text { HF/6-311G + (d,p) VIBRATIONAL } \\
\text { ASSIGNMENTS }\left(\mathrm{cm}^{-1}\right) \text { OF [EPy]Br }\end{array}$} \\
\hline Assignment & $v$ & $I R v_{\exp }^{12}$ \\
\hline Cat-An tors & 24 & \\
\hline Cat-An tors & 122 & \\
\hline Cat-An bend & 161 & \\
\hline Sym wag of C-H in pyridine ring & 445 & 482 \\
\hline Sym wag of $\mathrm{CH}_{2}$ group and $\mathrm{C}-\mathrm{H}$ in pyridine ring & 515 & \\
\hline Sym wag of $\mathrm{C}-\mathrm{H}$ in pyridine ring & 730 & 764 \\
\hline Asym wag of $\mathrm{C}-\mathrm{H}$ in pyridine ring & 847 & \\
\hline Sym wag of $\mathrm{C}-\mathrm{H}$ in pyridine ring & 936 & 973 \\
\hline Asym wag of C-H in ethyl group and pyridine ring & 1035 & 1028 \\
\hline Asym wag of C-H in ethyl group and pyridine ring & 1044 & 1061 \\
\hline Asym wag of $\mathrm{C}-\mathrm{H}$ in pyridine ring & 1090 & 1091 \\
\hline $\begin{array}{l}\text { op bend of pyridine ring and Asym wag of } \mathrm{C}-\mathrm{H} \text { in } \\
\text { pyridine ring }\end{array}$ & 1097 & 1096 \\
\hline Asym wag of C-H in ethyl group and pyridine ring & 1163 & 1176 \\
\hline Asym rock of terminal $\mathrm{CH}_{3}$ group & 1197 & \\
\hline ip scissor of $\mathrm{C}-\mathrm{H}$ in pyridine ring & 1215 & 1217 \\
\hline $\begin{array}{l}\text { ip scissor of } \mathrm{C}-\mathrm{H} \text { in pyridine ring and Asym rock } \\
\text { of terminal } \mathrm{CH}_{3} \text { group }\end{array}$ & 1262 & 1245 \\
\hline $\begin{array}{l}\text { Stretch of } \mathrm{N}^{-\mathrm{CH}_{2}} \text { and Asym rock of terminal } \mathrm{CH}_{3} \\
\text { group }\end{array}$ & 1289 & \\
\hline $\begin{array}{l}\text { ip scissor of } \mathrm{C}-\mathrm{H} \text { in pyridine ring and Asym rock } \\
\text { of terminal } \mathrm{CH}_{3} \text { group }\end{array}$ & 1329 & 1318 \\
\hline $\begin{array}{l}\text { ip scissor of } \mathrm{C}-\mathrm{H} \text { in pyridine ring and Asym rock } \\
\text { of terminal } \mathrm{CH}_{3} \text { group }\end{array}$ & 1331 & 1368 \\
\hline Asym wag of C-H in ethyl & 1429 & 1458 \\
\hline Asym wag of $\mathrm{C}-\mathrm{H}$ in pyridine ring & 1505 & 1500 \\
\hline Asym wag of $\mathrm{C}-\mathrm{H}$ in pyridine ring and ethyl & 1549 & \\
\hline Asym rock of terminal $\mathrm{CH}_{3}$ group & 1607 & 1583 \\
\hline Asym wag of C-H in pyridine ring and ethyl & 1638 & 1634 \\
\hline Stretch of $\mathrm{C}-\mathrm{N}$ in pyridine ring & 1769 & \\
\hline Stretch of $\mathrm{C}=\mathrm{C}$ in pyridine ring & 1829 & \\
\hline Stretch of $\mathrm{C}-\mathrm{H}$ in terminal $\mathrm{CH}_{3}$ group & 3171 & 3130 \\
\hline Stretch of C-H in ethyl & 3233 & \\
\hline Stretch of C-H in ethyl & 3235 & \\
\hline Stretch of C-H in ethyl & 3295 & \\
\hline Stretch of $\mathrm{C}-\mathrm{H}$ in pyridine ring & 3437 & 3436 \\
\hline
\end{tabular}

\section{Conclusion}

The molecular structure of the pre-optimization was built by semi-empirical PM3 method and then the [EPy]Br the optimal configuration were obtained by calculations of respectively the $6-31 \mathrm{G}+(\mathrm{d}, \mathrm{p})$ and $6-311 \mathrm{G}+(\mathrm{d}, \mathrm{p})$ basis set using B3LYP, B3PW91 and HF method). The results show that pyridine ring of $[\mathrm{EPy}] \mathrm{Br}$ is a little chair-type structure, there is charge transfer in the [EPy]Brions on the formation process that indicating $[\mathrm{EPy}]^{+}$and $\mathrm{Br}^{-}$ions have strong electrostatic attraction.

The infrared spectrum bands of [EPy]Br was calculated using the same method and the frequency of calculated and experimental dates was compared, the conclusion shows that the content of consistency of B3PW91/6-311G + (d,p) and $\mathrm{HF} / 6-311 \mathrm{G}+(\mathrm{d}, \mathrm{p})$ method was the highest and vibration frequencies can be sumed up and analyzed. Therefore, 
quantum chemical methods can be used to predict the IR spectral data of ionic liquids, such ionic liquids can be provided for the spectrum with the theoretical prediction and structureproperties relationship.

\section{ACKNOWLEDGEMENTS}

Financial assistance from Guangxi Department of Education Scientific Research Projects (201012MS123) and Guangxi Graduate Student Scientific Research Innovation Projects (2011105940817M03) are gratefully acknowledged.

\section{REFERENCES}

1. T. Welton, Chem. Rev., 99, 2071 (1999).

2. J.S. Moulthrop, R.P. Swatloski, G. Moyna and R.D. Rogers, Chem. Commun., 1557 (2005).
3. J. Kiefer and C.C. Pye, J. Phys. Chem. A., 114, 6713 (2010).

4. H. Olivier-Bourbigou, L. Magna and D. Morvan, Appl. Catal. A, 373, 1 (2010).

5. H. Shirota, J.F. Wishart and E.W. Castner Jr., J. Phys. Chem. B., 111, 4819 (2007).

6. E.A. Turner, C.C. Pye and R.D. Singer, J. Phys. Chem. A., 107, 2277 (2003).

7. K. Dong, S. Zhang, D. Wang and X. Yao, J. Phys. Chem. A., 110, 9775 (2006).

8. Y. Wang, H. Li and S. Han, J. Phys. Chem. A., 110, 24646 (2006)

9. V.N. Emel'yabebko, S.P. Vervkin and A. Heintz, J. Am. Chem. Soc., 129, 3930 (2007).

10. E.R. Talaty, S. Raja, V.J. Storhaug, A. Dolle and W.R. Carper, J. Phys. Chem. B., 108, 13177 (2004).

11. A.H. Pakiari, S. Siahrostami and T. Ziegler, J. Mol. Struct.: Theochem., 955, 47 (2010).

12. http://riodb01.ibase.aist.go.jp/sdbs/cgi-bin/direct_frame_top.cgi 